\title{
EVALUATION OF TEMPERAMENT IN PREGNANCY INDUCED HYPERTENSION CASES
}

\author{
Rahnuma Sayed", Naeela Ansari, Shaikh Ejaz Parvez \\ Farha Rizwan, Rehan Safee and Abdul Muttalib \\ Department of Tahaffuzi-wa-Samaji Tib \\ Z.V.M Unani Medical College, Pune, India
}

\section{Review Paper}

\section{ABSTRACT}

Pregnancy induced hypertension (PIH) is a worldwide concern; $22^{\text {nd }}$ may is remembered every year as the world preeclampsia day. According to the WHO, PIH is one of the main causes of maternal, fetal and neonatal mortality and morbidity. In a retrospective study over the period 2000-2009 in a tertiary center in India, PIH was the third cause of maternal death. Material and Methods: One time observational hospital based study Patients as per inclusion and exclusion criteria were selected for the study. Consent of the patient recorded.

No. of Pages: 5

References: 10

Keywords: Pregnancy induced hypertension, Imtala, Mizaj. pre-eclampsia.

\section{INTRODUCTION}

$\mathrm{PIH}$ is a worldwide concern; $22^{\text {nd }}$ may is remembered every year as the world Preeclampsia day. Pregnancy induced hypertension (PIH) is defined as BP $\geq 140 / 90 \mathrm{mmHg}$, taken after a period of rest on two occasions or $\geq 160 / 110 \mathrm{mmHg}$ on one occasion in a previously normotensive woman ${ }^{1}$

According to the WHO, PIH is one of the main causes of maternal, fetal and neonatal mortality and morbidity. In a retrospective study over the period 2000-2009 in a tertiary center in India, PIH was the third cause of maternal death.

Another study showed that the most common cause of mortality in cases of preeclampsia was hemolysis, elevated liver enzyme \& low platelet count [HELLP] or partial HELLP syndrome. [83.3\%].
Pregnancy induced hypertension complicates about 6-10\% of pregnancies. It is classified as mild [SBP 140-149 \& DBP 90-99mmHg], moderate [SBP 150-159 \& DBP 100$109 \mathrm{mmHg}$, and severe [SBP $\geq 160 \& \mathrm{DBP} \geq 110 \mathrm{mmHg}$. ${ }^{3}$

Temperament [MIZAJ] is derived from Arabic word “mazaj”, which means mixture, composition. ${ }^{6}$

Temperament can be defined as a new state which is the result of the actions \& reactions between the contrary qualities present in different elements. The resultant uniform state which emerges after the combination of the properties of more than one element is called temperament. ${ }^{6,7,8}$

The different temperaments are sanguineous, phlegmatic, melancholic, \& bilious. Each person possesses a dominant plus a subdominant temperament.

*Corresponding author: rehnumamukhtarsayyed@gmail.com 
In Unani system of medicine specific mizaj people is prone to specific disorders. e.g.:

- Balghami (Phlegmatic) mizaj are prone to asthma \& diseases related with Respiratory system.

- Saudawi or Melancholic's [black bile] are prone to psychological disorders.

- Similarly Damvi (sanguine) temperament persons are prone to hypertension \& blood related disorders,

- Safrawi (yellow bile) is prone to gastric ulcers, dysentry. ${ }^{2,8}$

\section{MATERIALAND METHODS}

One time observational hospital based study Patients as per inclusion and exclusion criteria were selected for the study. Consent of the patient recorded. Sample size is 500 .

Diagnosed cases of pregnancy induced hypertension in between the age of 20-45 years were included in the study. Womens with Multiple gestations, such as twins or triplets, pre-existing chronic conditions of (chronic hypertension, diabetes mellitus, gestational diabetes, obesity, chronic kidney disease, lupus, and vascular or connective tissue disorders) are not included in the study.

ASSESSMENT CRITERIA: (I) Mizaj assessment Proforma (Prepared by CCRUM) Based upon the Ajnas Ashra(II) Medical Record of cases.

\section{OBSERVATIONAND RESULTS}

Table 1) Age distribution of cases studied with PIH in the study group.

\begin{tabular}{|l|c|c|}
\hline Age Group (years) & No. of cases & \% of cases \\
\hline $20-24$ & 38 & 7.6 \\
\hline $25-29$ & 216 & 43.2 \\
\hline $30-34$ & 151 & 30.2 \\
\hline $35-40$ & 95 & 19.0 \\
\hline Total & 500 & 100.0 \\
\hline
\end{tabular}

500 cases studied, 38 (7.6\%) had age between 20 - 24 years, 216 (43.2\%) had age between 25 - 29 years, 151 (30.2\%) had age between 30 - 34 years and 95 (19.0\%) had age between $35-40$ years.

The distribution of mean \pm SD of age in the study group was $30.1 \pm 4.3$ years and the minimum - maximum age range was $20-40$ years.

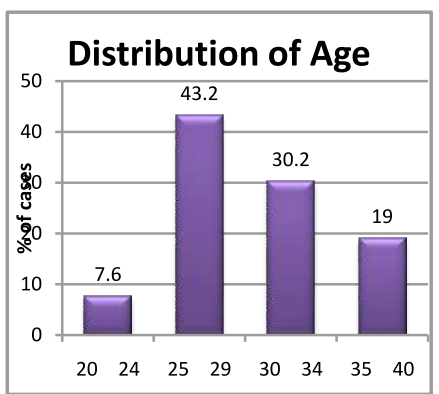

Figure no. 1 Age distribution of cases studied with PIH in the study group.

Table 2: Distribution of gravidity of cases studied with PIH according to temperament (Mizaj).

\begin{tabular}{|c|c|c|c|c|c|c|c|c|c|}
\hline \multirow[b]{2}{*}{ Gravidity } & \multicolumn{2}{|c|}{ Damvi (n=243) } & \multicolumn{2}{|c|}{ Balghami $(n=115)$} & \multicolumn{2}{|c|}{ Safrawi $(n=91)$} & \multicolumn{2}{|c|}{ Saudawi $(n=51)$} & \multirow[b]{2}{*}{ P-value } \\
\hline & $\mathbf{n}$ & $\%$ & $\mathbf{n}$ & $\%$ & $\mathbf{N}$ & $\%$ & $\mathbf{n}$ & $\%$ & \\
\hline 1 & 70 & 28.8 & 29 & 25.2 & 48 & 52.7 & 26 & 51.0 & $0.001 * * *$ \\
\hline 2 & 70 & 28.8 & 42 & 36.5 & 24 & 26.4 & 11 & 21.6 & \\
\hline 3 & 60 & 24.7 & 30 & 26.1 & 11 & 12.1 & 6 & 11.8 & \\
\hline$>3$ & 43 & 17.7 & 14 & 12.2 & 8 & 8.8 & 8 & 15.7 & \\
\hline Total & 243 & 100.0 & 115 & 100.0 & 91 & 100.0 & 51 & 100.0 & \\
\hline
\end{tabular}

P-value by Chi-Square test. P-value $<0.05$ is considered to be statistically significant. ***P-value $<0.001$

The distribution of gravidity of cases studied with PIH differs significantly across various temperament groups in the study group (P-value<0.001). 


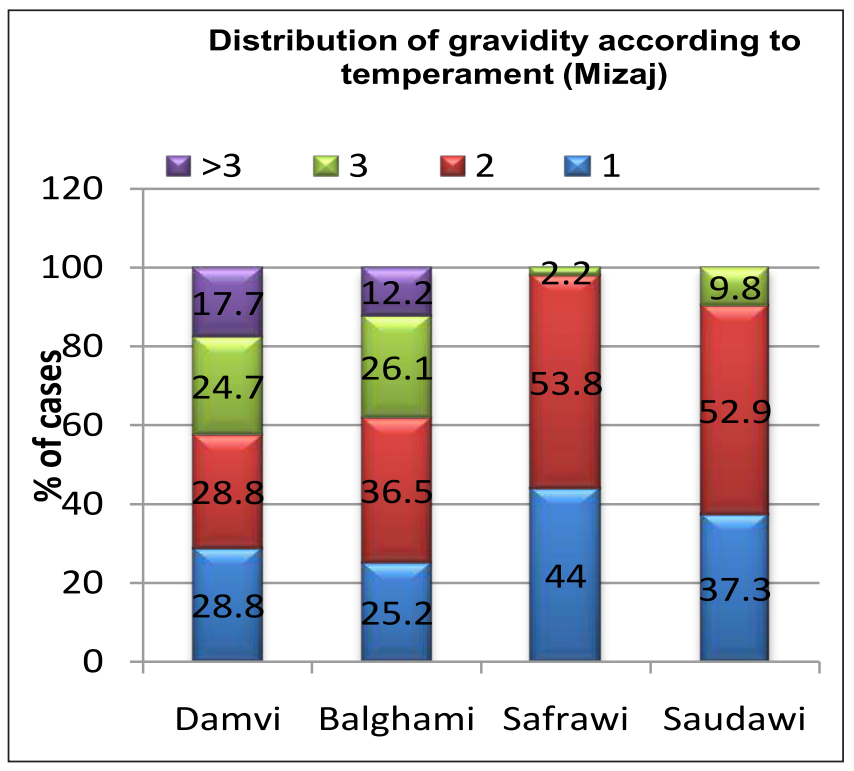

Figure: 2 Distribution of gravidity of cases studied with PIH according to temperament (Mizaj).

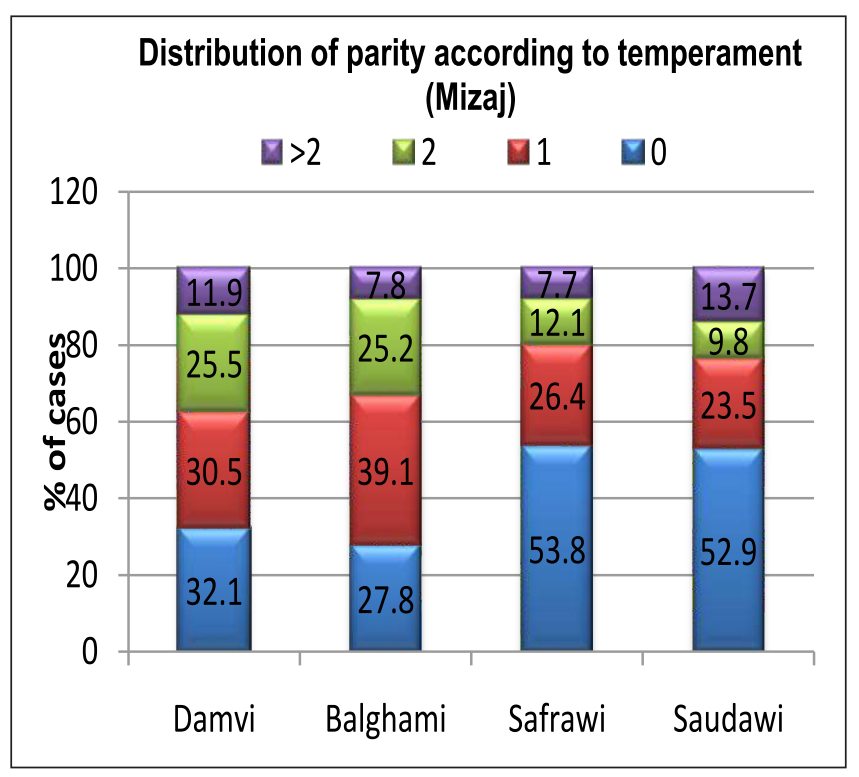

Figure 3: Distribution of parity of cases studied with PIH according to temperament (Mizaj).

Table 3:Distribution of parity of cases studied with PIH according to temperament (Mizaj).

\begin{tabular}{|c|c|c|c|c|c|c|c|c|c|}
\hline \multirow[b]{2}{*}{ Gravidity } & \multicolumn{2}{|c|}{ Damvi (n=243) } & \multicolumn{2}{|c|}{ Balghami (n=115) } & \multicolumn{2}{|c|}{ Safrawi (n=91) } & \multicolumn{2}{|c|}{ Saudawi $(n=51)$} & \multirow[b]{2}{*}{ P-value } \\
\hline & $\mathbf{n}$ & $\%$ & $\mathbf{n}$ & $\%$ & $\mathbf{N}$ & $\%$ & $\mathbf{n}$ & $\%$ & \\
\hline 0 & 78 & 32.1 & 32 & 27.8 & 49 & 53.8 & 27 & 52.9 & $0.001 * * *$ \\
\hline 1 & 74 & 30.5 & 45 & 39.1 & 24 & 26.4 & 12 & 23.5 & \\
\hline 2 & 62 & 25.5 & 29 & 25.2 & 11 & 12.1 & 5 & 9.8 & \\
\hline$>2$ & 29 & 11.9 & 9 & 7.8 & 7 & 7.7 & 7 & 13.7 & \\
\hline Total & 243 & 100.0 & 115 & 100.0 & 91 & 100.0 & 51 & 100.0 & \\
\hline
\end{tabular}

The distribution of parity of cases studied with PIH differs significantly across various temperament groups in the study group (P-value<0.001).

Table 4: Distribution of temperament (Mizaj) among the cases studied with PIH.

\begin{tabular}{|l|c|c|}
\hline Temperament & No. of cases & \% of cases \\
\hline Damvi & 243 & 48.6 \\
\hline Balghami & 115 & 18.2 \\
\hline Safrawi & 91 & 10.2 \\
\hline Saudawi & 51 & 100.0 \\
\hline Total & 500 & \\
\hline
\end{tabular}

Of 500 cases studied with PIH, 243 (48.6\%) had Damvi Mizaj, 115 (23.0\%) had Balghami Mizaj, 91 (18.2\%) had Safrawi Mizaj and $51(10.2 \%)$ had Saudawi Mizaj. 


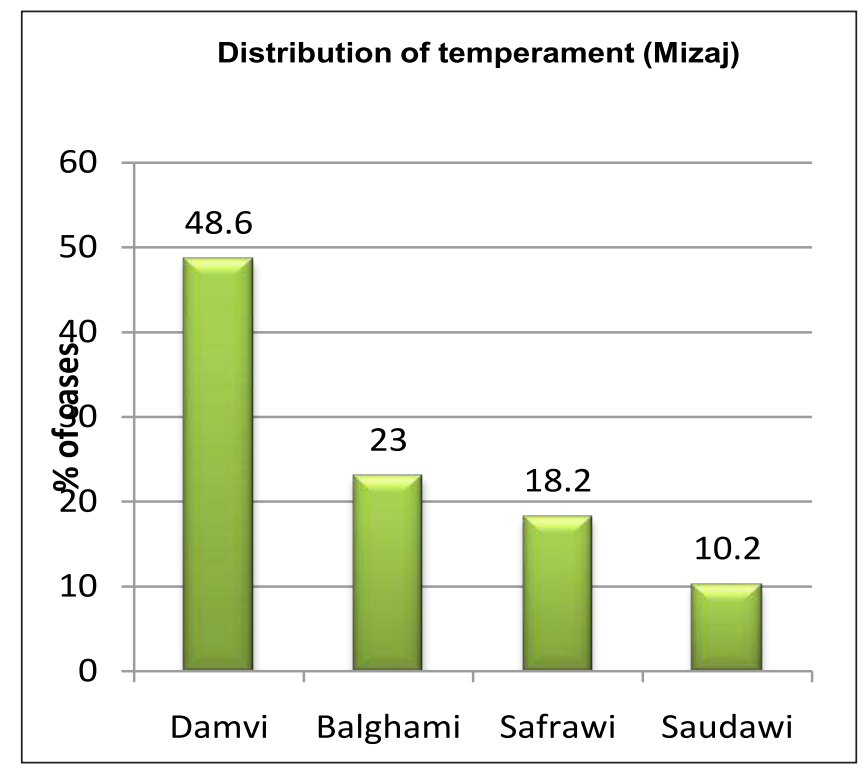
Table 4: Distribution of temperament (Mizaj)
among the cases studied with PIH.

\section{DISCUSSION}

(Table no.1 \& Figure no.1) shows that Age distribution of cases studied with PIH, of 500 cases were studied, among them 38 (7.6\%) were of age between 20 - 24 years, 216 (43.2\%) were of age between 25 - 29 years, 151 (30.2\%) were of age between 30 - 34 years and 95 (19.0\%) were of age between $35-40$ years. The distribution of mean \pm SD of age in the study group was $30.1 \pm 4.3$ years and the minimum - maximum age range was $20-40$ years.

(Table no.2 \& Figure no.2), shows distribution of gravidity of cases studied with PIH according to temperament (Mizaj) Women with gravidity 1 had safrawi Mizaj (52.7\%). 36.5\% \& 26.1\% PIH women with gravidity 2 \& 3 found to be Balghami Mizaj respectively. 15.7\% PIH women having gravidity more than 3 were observing to be Saudawi Mizaj.

The distribution of gravidity of cases studied with PIH differs significantly across various temperament groups in the study group (P-value $<0.001)$.

(Table no.3 \& Figure no.3) shows distribution of parity of cases studied with PIH according to temperament (Mizaj), Maximum PIH women with no parity were observed to be Saudawi mizaj (52.9\%)Women with 1 parity had Balghami Mizaj (39.1\%), followed by (25.5\%) \& 13.7\% women with parity 2 and more than 2 had Damvi \& Saudawi mizaj respectively.

The distribution of parity of cases studied with PIH differs significantly across various temperament groups in the study group (P-value $<0.001)$.
(Table no.4 \& Figure no.4) shows that distribution of temperament (Mizaj) among the cases studied with PIH Of the 500 cases studied with PIH, 243 (48.6\%) had Damvi Mizaj, 115 (23.0\%) had Balghami Mizaj, 91 (18.2\%) had Safrawi Mizaj and 51 (10.2\%) had Saudawi Mizaj, indicating that PIH has a stronger association with sanguine temperament followed in descending order with phlegmatic, choleric and melancholic temperaments.

Similarly Iqbal farooq Ahmed conducted a study in Kottigepalya (Bangalore) in which he observed that hypertension has a stronger association with sanguine temperament. $^{10}$

\section{CONCLUSION}

The present study conducted in the city to find the temperament of cases of PIH. In the present study the distribution of temperament (Mizaj) among the cases studied with PIH of 500 cases studied with PIH, 243 (48.6\%) had Damvi Mizaj, 115 (23.0\%) had Balghami Mizaj, 91 (18.2\%) had Safrawi Mizaj and 51 (10.2\%) had saudawi Mizaj, indicating that $\mathrm{PIH}$ has a stronger association with sanguine temperament followed in descending order with phlegmatic, choleric and melancholic temperaments.

A highly significant difference was observed on gravidity, parity, of cases studied with PIH according to temperament (Mizaj).

\section{SUMMARY}

Pregnancy induced hypertension (PIH) is defined as $\mathrm{BP} \geq$ $140 / 90 \mathrm{mmHg}$, taken after a period of rest on two occasions or $\geq 160 / 110 \mathrm{mmHg}$ on one occasion in a previously normotensive woman

Mohd.Bin Zakariya Razi stated in his book "Kitab-ulmurshid" the term hypertension has not been used as such by Unani physicians and the term Zaghtuddam qavi was adopted by the Unani authors as a translation of hypertension. Ancient Unani scholars used a term Imtala to describe a condition in which normal or abnormal fluids are too much accumulated in the body producing certain type of symptoms. ${ }^{5}$ the clinical symptoms of Imtala bil hasbil auiya described by the Unani physicians are very similar to that of hypertension.,

In about 12 percent of first pregnancies in previously normotensive women, hypertension appears after 20 weeks [gestational hypertension]. In about half of cases, this hypertension will progress to preeclampsia when complicated by proteinuria, edema, or haematological or hepatic abnormalities, which, in turn, increases the risk of progress to eclampsia, defined by the occurrence of convulsions. Women with hypertension predating pregnancy have an even higher incidence of preeclampsia and a greater likelihood of early delivery of small for gestational age babies. Preeclampsia is of unknown cause but occurs more frequently in primigravida women and in pregnancies 
involving men or women who were the product of a pregnancy complicated by preeclampsia, supporting a genetic role. $^{9}$

Distribution of temperament (Mizaj) among the cases studied with PIH of 500 cases studied with PIH, 243 (48.6\%) had Damvi Mizaj, 115 (23.0\%) had Balghami Mizaj, 91 (18.2\%) had Safrawi Mizaj and 51 (10.2\%) had Saudawi Mizaj, indicating that PIH has a stronger association with sanguine temperament followed in descending order with phlegmatic, choleric and melancholic temperaments.

A highly significant difference was observed on gravidity, Parity of cases studied with PIH according to temperament (Mizaj).

\section{BIBLIOGRAPHY:}

1. Sibai, Baha.M. Diagnosis and Management of Gestational Hypertension and Preeclampsia. Obstetrics and Gynecology 2003 July; 102(1), 181-92

2. Nafisi AB, Translated by Mohd.K. Kulliyat-e-Nafisi. Idara Kitab ul Shaifa, Darya Ganj, New Delhi: 1934: P19, 196-200, 121,319.

3. Evangelia K,Sophia P,George $\mathbf{K}$, et.al. Pregnancyinduced hypertension:Hormones 2015, 14 (2): 211-223.
4. Ahmed S. et al. Clinical Efficacy of a Unani Formulation on the Subjective Parameters of Zaghtuddam Qavi Ibtidai (Primary Hypertension). Published in journal of the international society for the history of Islamic medicine (JISHIM). 2015: vol. 14-15, P. 56-57.

5. Razi BZ. Translated by Mohd.razi ul Islam Nadvi. Kitab ul murshid. Part 1.2000: taraqi urdu beuro, new delhi, july-sep 1994; pg no.64-65.

6. Ansari ZA. al umur al tabiya: mizaj: 1999: Ejaz publishing House; p-21 to p-53.

7. Ahmad JH. Unani The science of Graeco-Arabic Medicine. Published by Roli Books; P.23-26, P. 42.

8. Sayed KH. Usool-e-tib. Published by Urdu Accademy Lucknow.U.P: 1980: P.23-32, 42, 47-48, 284,467, 486.

9. Ronald G. Victor, Norman M.kalpan. systemic hypertension: mechanism and diagnosis: 8th edition; pg.no.1044.

10. Iqbal F.A. A study on prevalence of Zaghtuddam qavi (hypertension) in specified population of Kottigepalya and its association with mizaj (temperament): MD (Unani): thesis submitted tothe Rajiv Gandhi University of Health Sciences, Karnataka, Bangalore, 2007. 